77. The DCCT/EDIC study research groop. Long-term effect of diabetes and its treatment on cognitive function. $\mathrm{N}$ Engl $\mathrm{J}$ Med 2007;356:1842-52.

78. UK Prospective Diabetes Study Group. Tight blood pressure control and risk of macrovascular and microvascular complications in type 2 diabetes: UKPDS. Br Med J 1998;317:703-13.

79. UK Prospective Diabetes Study Group: Effect of intensive blood-glucose control with metformin on complications in overweight patients with type 2 diabetes (UKPDS 34). Lancet 1998;352:854-65.

80. UK Prospective Diabetes Study Group:
Intensive blood-glucose control with sulphonylureas or insulin compared with conventional treatment and risk of complications in patients with type 2 diabetes (UKPDS 33). Lancet 1998;352:837-53.

81. Manschot S.M., Biessels G.J., Cameron N.E. et al. Angiotensin converting enzyme inhibition partially prevents deficits in water maze performance, hippocampal synaptic plasticity and cere,hfk blood flow in streptozotocin-diabetic rat. Brain Res 2003;966(2):274-82.

82. Sima A.A., Li Z.G. The effect of C-peptide on cognitive dysfunction and hippocampal apoptosis in type 1 diabetic rats. Diabetes
2005;54:1497-505.

83. Kamboj S.S., Sandhir R. Protective effect of $\mathrm{N}$-acetylcysteine supplementation on mitochondrial oxidative stress and mitochondrial enzymes in cerebral cortex of streptozotocintreated diabetic rats. Mitochondron 2011;11(1):214-22.

84. Захаров В.В., Сосина В.Б. Применение антигипоксантов в лечении когнитивных нарушений у больных сахарным диабетом. Неврол журн 2008;5:39-43.

85. Ziegler D., Movsesyan L., Mancovsky B. et al. Treatment of symptomatic polyneuropathy with Actovegin in type 2 diabetic patients. Diabetes Care 2009;32:1479-84.

\title{
О.С. Зайщев
}

\section{Нейропсихиатрические аспекты тяжелых повреждений мозга}

\begin{abstract}
Дана оценка состоянию отечественной нейропсихиатрии, приоритетным разработкам в области различных психопатологических синдромов при тяжелых повреждениях мозга. С позиций представления об организации психической деятельности во времени объяснены многие когнитивные и эмоциональные расстройства. Подчеркивается, что восстановление психической деятельности обеспечивается достижением преморбидных уровней межполушарного взаимодействия и функциональной асимметрии больших полушарий мозга. Обобщен опыт изучения, классификации и терапии различных психических нарушений, возникающих после тяжелых травм мозга. Сформулированы основные принципы психофармакотерапии и реабилитации пострадавщих.
\end{abstract}

Ключевые слова: нейропсихиатрия, черепно-мозговая травма, функциональная асимметрия, межполушарное взаимодействие, психофармакотерапия, нейрореабилитация.

Контакты: Олег Семенович Зайцев оzаitsev@nsi.ru

\section{Neuropsychiatric aspects of severe brain injuries O.S. Zaitsev \\ N.N. Burdenko Institute of Neurosurgery, Russian Academy of Medical Sciences, Moscow}

The state-of-the-art of Russian neuropsychiatry and priority developments in different psychopathological syndromes in severe brain injuries are assessed. Many cognitive and emotional impairments are explained in terms of the idea on the organization of psychic activity over time. It is emphasized that to achieve the premorbid levels of an interhemispheric interaction and functional asymmetry of the cerebral hemispheres affords psychic activity recovery. The experience in investigating, classifying, and treating various mental disorders occurring after severe brain injuries is generalized. The basic principles of psychopharmacotherapy and rehabilitation of victims are stated.

Key words: neuropsychiatry, brain injury, functional asymmetry, interhemispheric interaction, psychopharmacotherapy, neurorehabilitation. Contact: Oleg Semenovich Zaitsev ozaitsev@nsi.ru

Нейропсихиатрия - наука о диагностике и лечении психических нарушений, обусловленных патологией нервной системы. Эта дисциплина находится на стыке психиатрии, неврологии, нейрохирургии, нейрореаниматологии и нейрореабилитации и в последние годы стремительно развивается, опираясь на все более обширные и достоверные данные нейропсихологии, нейровизуализации и нейрохимии. Нейропсихиатрия воспринимается неоднозначно: с одной стороны, ее игнорируют и утверждают, что «нет такой специальности», с другой - неоправданно расширяют ее границы, обосновывая это тем, что «вся психопатология опосредуется через мозг», но чаще всего нейропсихиатрию пытаются ограничить очень узкими рамками - исключительно смежными между неврологией и психиатрией заболеваниями, в основном эпилепсией и деменцией.

Любые, даже, казалось бы, сугубо неврологические признаки (парез, гиперкинез, тремор, фокальная судорога) имеют психопатологическую составляющую. Они различны по клинической сути и прогнозу и зависят от того, как пациент реагирует на этот феномен. Так, у правшей с преимущественным поражением правого полушария преобладают облегченное восприятие, преуменьшение значения симпто- 


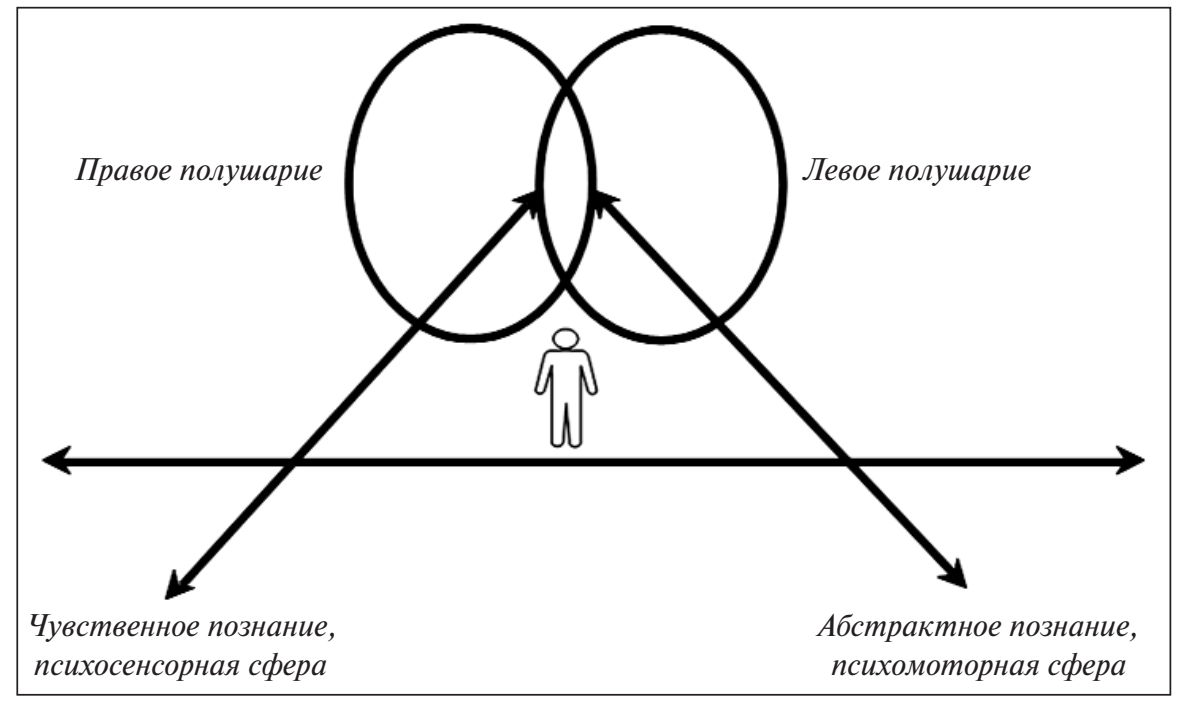

Рис. 1. Организация психической деятельности во времени - результат взаимодействия и асимметрии полушарий мозга у правщей

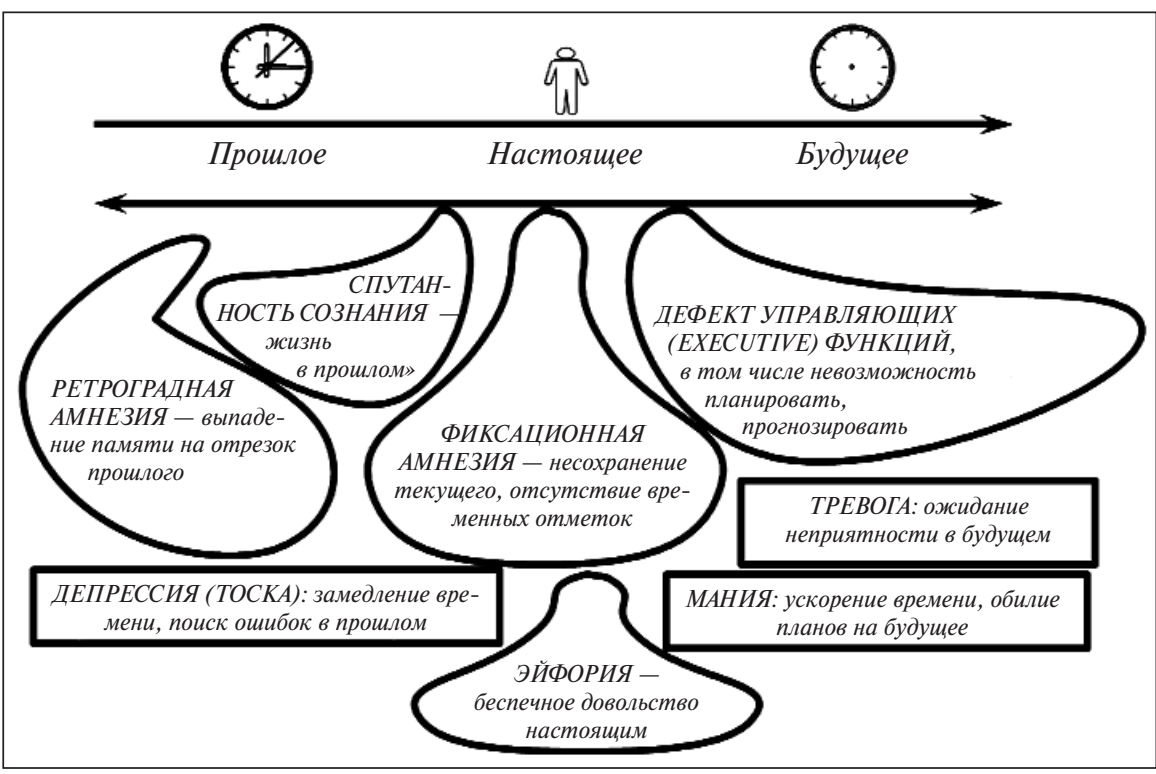

Рис. 2. Дезорганизация психической деятельности во времени как основа различных психопатологических синдромов

ма, а при левостороннем поражении, наоборот, - фиксация на болезненных проявлениях, преувеличенная обеспокоенность ими.

Правильному пониманию объекта, целей и задач нейропсихиатрии в нашей стране препятствует крайне слабое ее освещение в отечественной литературе. На единственные пока русскоязычные руководство [1] и небольшой сборник [2] приходится множество зарубежных изданий [3-14].

Между тем отечественная нейропсихиатрия не только опирается на достижения других нейронаук, но и имеет собственные фундаментальные разработки. Одной из них является предложенное выдающимися российскими учеными Т.А. Доброхотовой и Н.Н. Брагиной (психиатром и неврологом) представление о пространственно-временной организации психической деятельности как результате взаимодействия и асимметрии больших полушарий головного моз- га $[15,16]$. Согласно этому представлению, у правшей левое полушарие, обеспечивая абстрактное познание, психомоторную сферу, как бы «живет» в настоящем и будущем, а правое, осуществляя чувственное познание, психосенсорную сферу, - в настоящем и прошлом (рис. 1).

У левшей нет такой специализации полушарий, поэтому они могут «чувствовать» («помнить») будущее, тревожиться (а не тосковать, как правши) о прошлом. Отсюда феномены предвосхищения, предвидения в пароксизмальной психопатологии левшей.

Это представление помогает понять сущность, происхождение и многих других синдромов (рис. 2).

Для дисфункции правого полушария у правшей характерны психопатологические симптомокомплексы, касаюшиеся прошлого, в частности ретроградная амнезия и депрессия (тоска), а для дисфункции левого дефекты планирования и тревога. Основным отличием мании от эйфории является устремленность маниакального аффекта в будущее, о чем можно судить по обилию высказываемых пациентом планов.

С помощью этих теоретических предпосылок можно по-особому взглянуть и на всю нейропсихиатрическую реабилитацию в целом. Ее цель - восстановление трехвременной структуры психической деятельности, которая опирается на прошлый опыт, осуществляется в настоящем и завершается значимым результатом в будущем, что обеспечивается восстановлением: 1) межполушарного взаимодействия и 2) функциональной асимметрии мозга.

Именно перспективы восстановления психической деятельности после тяжелых повреждений мозга, возможности оптимизировать этот процесс были и остаются в центре внимания нейропсихиатров.

Об актуальности проблемы нейротравмы красноречиво свидетельствуют эпидемиологические данные. Ежегодно в России черепно-мозговую травму (ЧМТ) получают 600 тыс. человек, почти 9\% из них становятся инвалидами. В настоящее время 2 млн жителей страны страдают от стойких тяжелых последствий ЧМТ [17]. Увеличивается число пострадавших, спасенных нейрохирургами и реаниматологами после все более тяжелых повреждений мозга.

Среди первичных повреждающих мозг факторов, которые воздействуют на пострадавших, - ударно-противоударное воздействие, вращение и угловое ускорение. Именно эти первичные факторы в комплексе со вторичными (гипотензия, гипоксия) зачастую и приводят к затяжной, мало- 


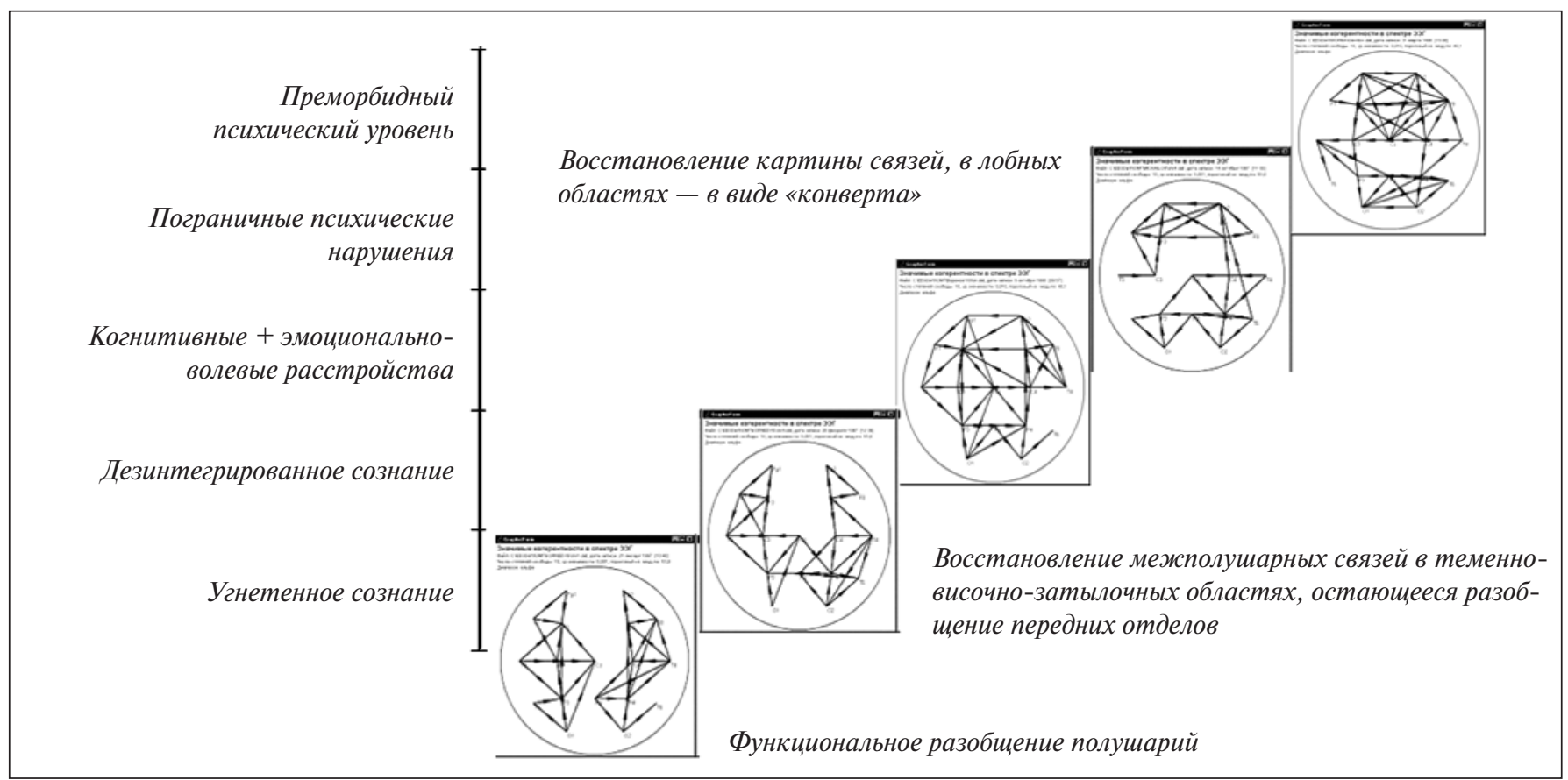

Рис. 3. Пространственное распределение когерентного $\alpha$-ритма ЭЭГ на разных уровнях психопатологической симптоматики после тяжелой ЧМТ

обратимой психической патологии, требующей нейропсихиатрического лечения.

При затяжных расстройствах сознания страдают не только и не столько полушарные, сколько глубинные - стволовые и подкорковые - структуры.

Далеко не всегда посттравматическую патологию можно увидеть при рутинной компьютерной (КТ) и магнитно-резонансной (МРТ) томографии, для их верификации приходится привлекать современные методы нейровизуализации, которые позволяют уточнять не только структурные, но и гемодинамические и нейрометаболические нарушения. Крайне интересны данные, получаемые с помощью пока не внедренной в широкую практику функциональной МРТ. Относительное совпадение участков активизации мозгового вещества у пациента с отсутствием внешних признаков сознания и у здорового в ответ на просьбу представить какой-нибудь процесс (например, игру в теннис) позволяет в некоторых наблюдениях предположить (а возможно, и подтвердить) присутствие сознания [18].

Весьма продуктивны и отечественные нейрофизиологические исследования. Как было показано О.М. Гриндель и соавт. [19], у пострадавших с тяжелой ЧМТ долгим и далеко не всегда возможным оказывается восстановление межполушарного взаимодействия (рис. 3). Оно отсут-

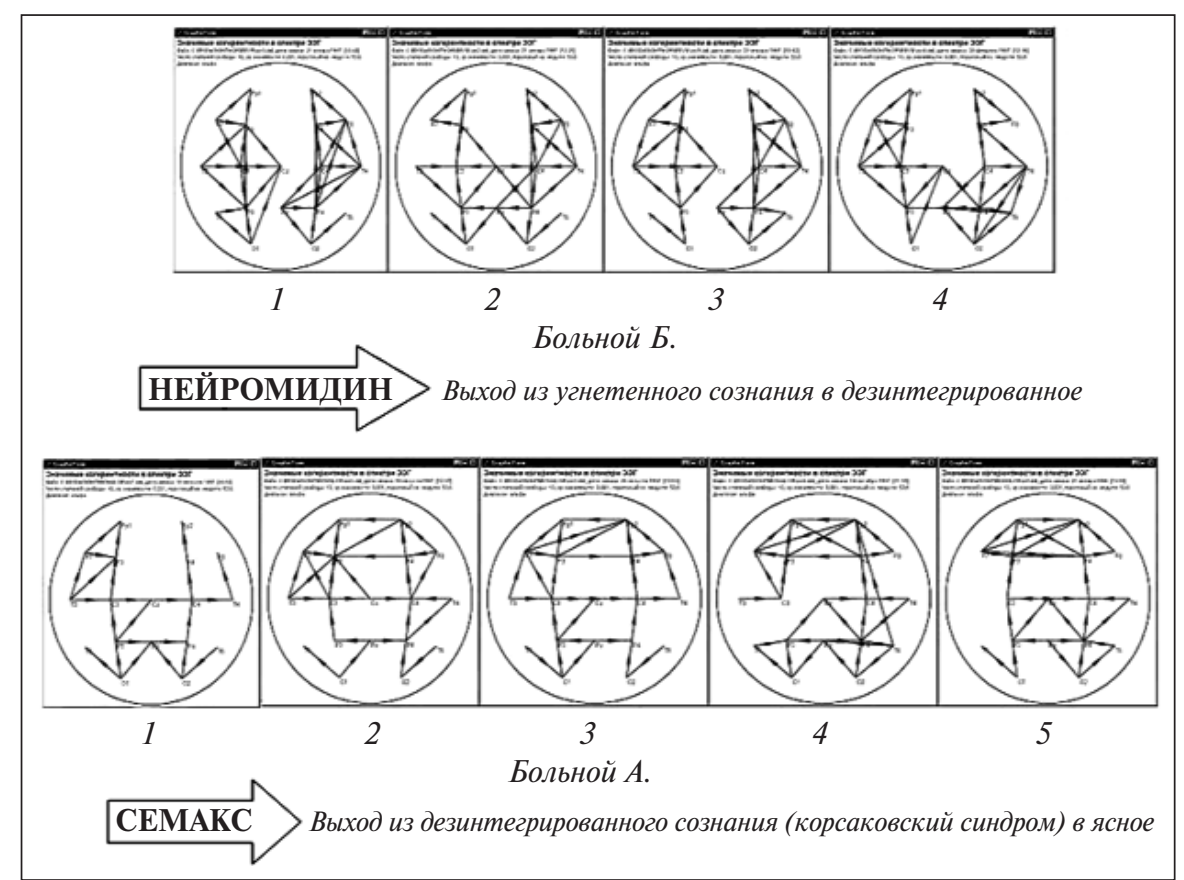

Рис. 4. Динамика межполушарной когерентности а-ритма ЭЭГ на фоне фармакотерапии нейромидином с восстановлением связей по задним отделам полушарий у больного Б. и семаксом с восстановлением связей между передними отделами мозга у больного А.

ствует при угнетенном сознании, оказывается частичным (распространяющимся только на задние отделы полушарий) при синдромах дезинтеграции (спутанности, корсаковском синдроме) и остается дефектным в дальнейшем, далеким от характерной для нормы формы «конверта»в лобных областях. 


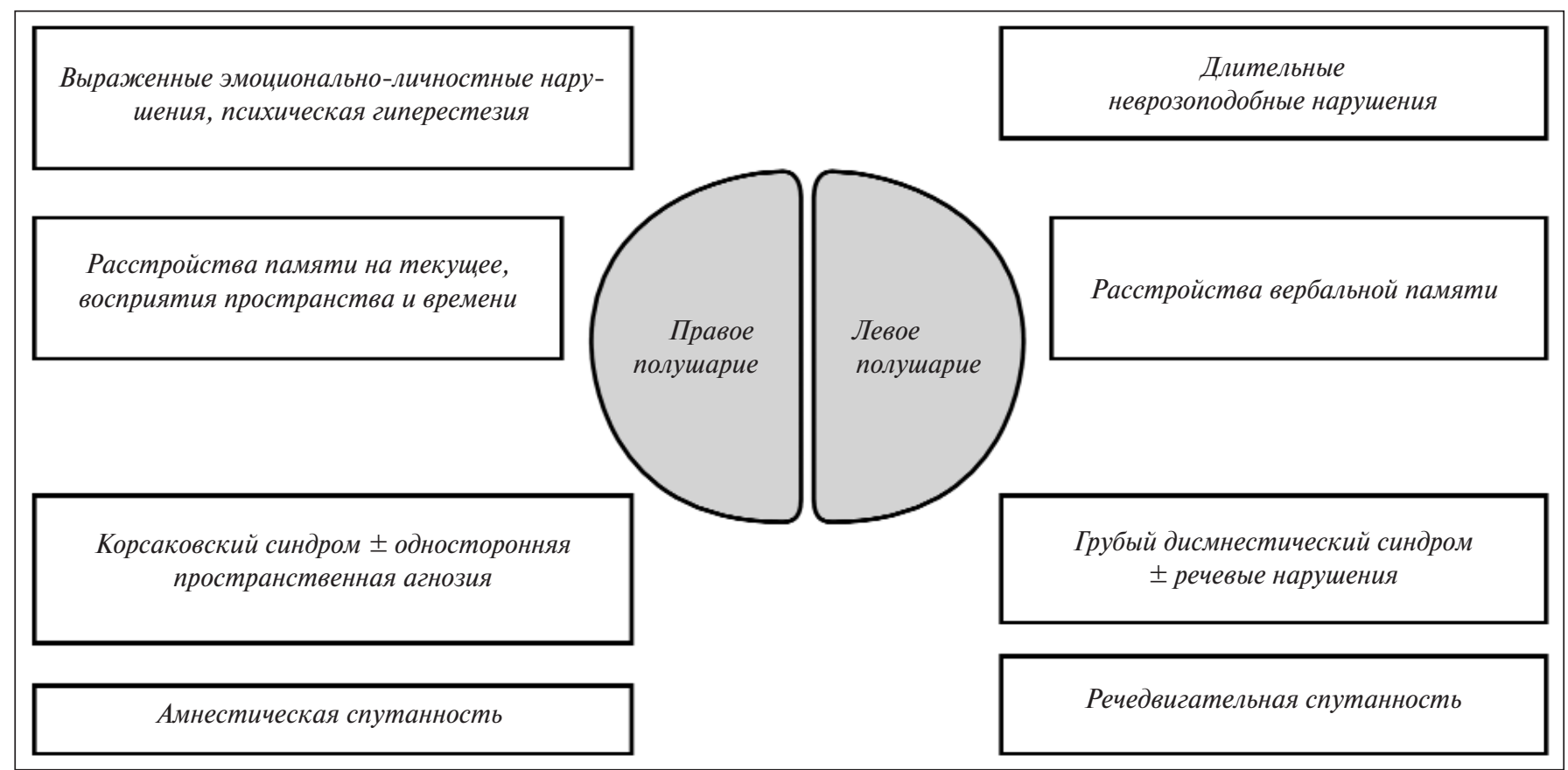

Рис. 5. Сторона преимущественного повреждения мозга и особенности психопатологической симптоматики по данным анализа тяжелой ЧМТ (без наблюдений с симметричным и глубинным подкорковым, орально-стволовым поражением)

Мониторинг межполушарного взаимодействия может свидетельствовать об эффективности различных, в том числе фармакотерапевтических, воздействий. Так, на рис. 4 видно, как на фоне лечения нейромидином восстановилась когерентность в задних отделах полушарий, что привело к выходу из состояния угнетенного сознания, а на фоне лечения семаксом нормализовались связи между лобными областями, что в конечном счете привело к восстановлению ориентации, выходу из корсаковского синдрома.

К сожалению, восстановление взаимодействия между полушариями не всегда достижимо, в том числе из-за структурных повреждений, атрофии мозолистого тела [19]. Так, при хроническом вегетативном состоянии и хроническом корсаковском синдроме магнитно-резонансная трактография позволяет выявить тотальную атрофию (полное «облысение») мозолистого тела в первом случае и частичную, распространяющуюся на лобные доли, - во втором. В этих случаях с помощью реабилитации можно ожидать лишь некоторого ослабления симптоматики в рамках прежнего синдрома.

Только после восстановления межполушарного взаимодействия начинают выявляться приведенные на рис. 5 различия между группами с преимущественным поражением левого и правого полушарий [20]. Они отсутствуют в период угнетенного сознания и обнаруживаются, лишь когда появляются синдромы спутанности. При правополушарном поражении достоверно чаще отмечаются амнестическая спутанность, корсаковский синдром с конфабуляциями, односторонняя пространственная агнозия, а в дальнейшем расстройства памяти на текущие события, нарушение чувства времени и пространства, выраженные эмоциональноличностные нарушения и психическая гиперестезия. При левополушарном поражении наблюдаются речедвигательная спутанность, грубый дисмнестический синдром, расстройства вербальной памяти, длительные неврозоподобные нарушения.
При глубинных (подкорково-диэнцефальных, стволовых) поражениях в отличие от полушарных чаще приходится иметь дело с состояниями, ранее практически не встречавшимися, - длительной комой, затяжными и хроническими бессознательными процессами (вегетативным статусом, акинетическим и гиперкинетическим вариантами мутизма), затяжной спутанностью, хроническим корсаковским синдромом, последующими многообразными когнитивными и эмоционально-волевыми нарушениями. Восстановление психической деятельности при этом зачастую оказывается неполным, длится месяцы и годы.

Трудности психопатологической квалификации посткоматозных состояний вынуждают при их оценке использовать разные, отличные от традиционных, подходы и терминологию. Если на входе в кому приемлемы устоявшиеся в медицине понятия «оглушение», «сопор», то после комы речь идет уже о стадиях-ступеньках выхода из нее.

После длительной (более 10 сут) комы постепенное восстановление психической деятельности может быть представлено в виде стадий, в начале которых появляется вполне определенный признак восстановления: 1) открывание глаз; 2) фиксация взора и слежения; 3) эмоциональные реакции на окружающих; 4) выполнение команд; 5) попытки речи; 6) ответы на вопросы; 7) ориентация; 8) эффективность познавательных процессов и волевых усилий; 9) адекватность реакций и преморбидной психической адаптации.

Для оценки всех тяжелых ЧМТ (при которых кома также обязательна, но может длиться меньше - от 12 ч) такие представления уже не подходят, поскольку нередко некоторые стадии пропускаются, отмечается одновременное появление различных признаков восстановления.

Такие часто выпадающие стадии могут быть объединены в четыре уровня симптоматики, возможной во всех периодах ЧМТ [20]: 


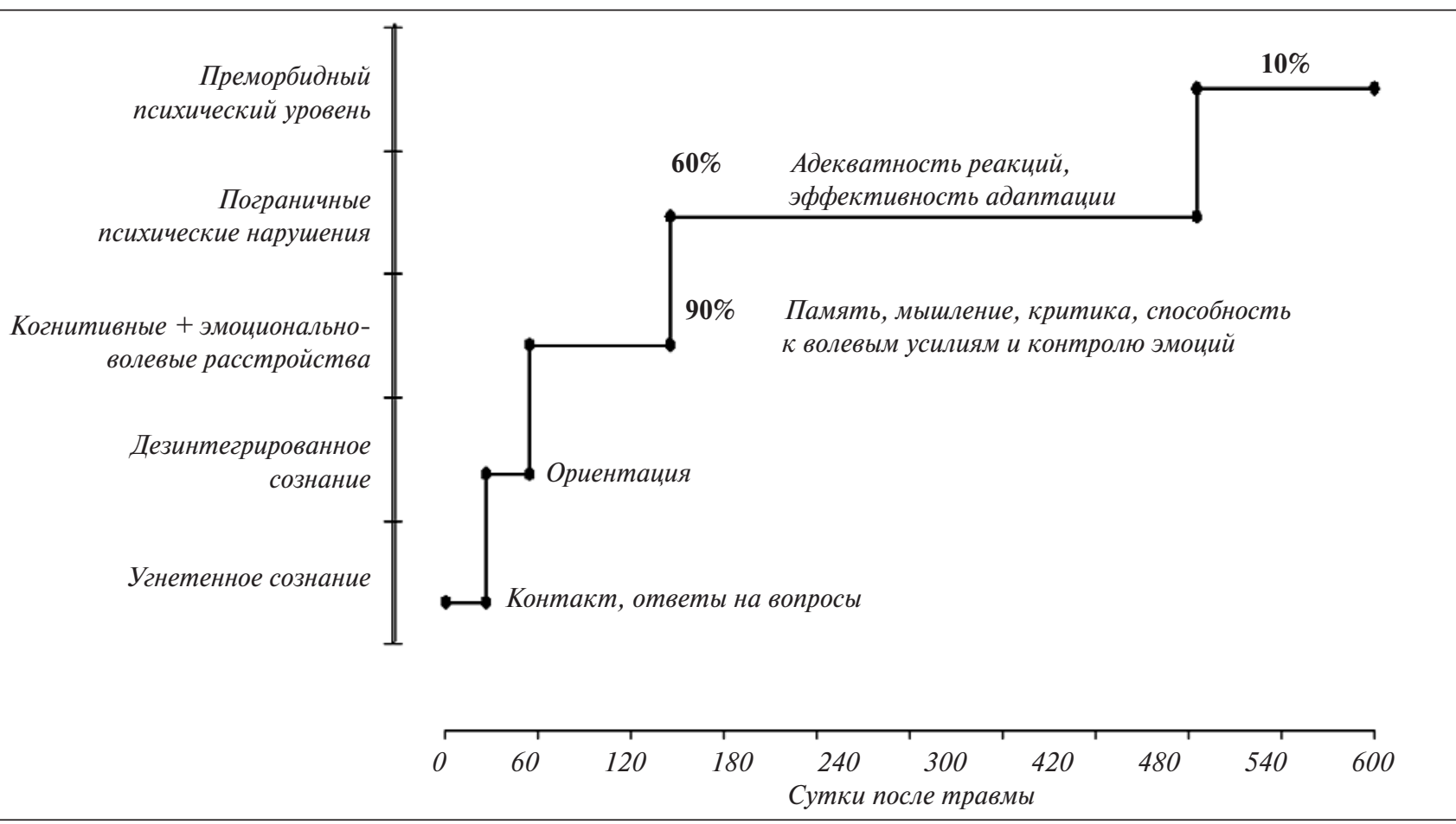

Рис. 6. Уровни симптоматики и восстановление психической деятельности: средние сроки появления ключевых признаков после тяжелой ЧМТ и процент пострадавших, достигших соответствующего уровня

1) угнетенное сознание с отсутствием или крайне неполным восстановлением контакта;

2) дезинтегрированное сознание с наличием контакта, но отсутствием ориентации в окружающем;

3) когнитивные и эмоционально-волевые расстройства на фоне формально ясного сознания, восстановленной ориентации;

4) пограничные (умеренные когнитивные, эмоционально-личностные, неврозоподобные) психические нарушения, проявляющиеся скорее не в повседневной деятельности, а в нестандартных ситуациях, требующих напряжения и адаптации.

Представление о средней скорости восстановления у пациентов с тяжелой ЧМТ дает рис. 6, на котором видно, что все формальные признаки ясного сознания (контакт, ориентация) восстанавливаются у больных в среднем примерно через 2 мес, основные когнитивные и эмоциональноволевые процессы - через полгода. В дальнейшем у $10 \%$ пациентов так и не нормализуются признаки ясного сознания, у $30 \%$ остаются грубые когнитивные и эмоциональноволевые нарушения, а у 50\% - пограничные. И только у 1 из 10 пациентов восстанавливается преморбидный уровень психической адаптации.

Прогноз восстановления психической деятельности складывается из многих факторов. Нейропсихиатрическая реабилитация имеет значение лишь при учете всех факторов, в первую очередь глубины поражения мозга, наличия артериальной гипотензии и гипоксии в остром периоде ЧМТ. В силу такой полифакторности в большинстве современных исследований тяжелой ЧМТ точность предсказания крайне редко превышает $70 \%$.

Многочисленные методы реабилитации должны применяться комплексно, но важнейшая роль среди них при- надлежит психофармакотерапии, которая все в большей степени становится базисом, без которого все остальное лечение может быть малоэффективным. Необходимы поиск и создание препаратов, ускоряющих восстановление психической деятельности, корригирующих нежелательные психические проявления. Конечно, эти препараты не входят и, может быть, никогда не войдут в стандарты лечения пострадавших. Однако по мере выхода из комы сама ситуация становится все более нестандартной, и это требует индивидуального подхода с использованием уже не стандартов, а выбора той или иной фармакологической стратегии.

Группой психиатрических исследований НИИ нейрохирургии им. Н.Н. Бурденко накоплен большой опыт изучения и применения психотропных препаратов. Здесь впервые у больных с ЧМТ использовали ноотропил, нейромидин, кортексин и семакс, систематически назначают фенибут, пантогам, ПК-Мерц. Сформулировать какие-либо стандарты пока не удалось, но обозначить пути оптимизации психофармакотерапии можно.

Не только в нашей стране, но и за рубежом пока нет исследований, которые бы легли в основу стандартов лечения психопатологических последствий ЧМТ. Так, в одном из последних метаанализов многочисленных англоязычных исследований сформулировано только несколько весьма относительных рекомендаций [22], причем в них говорится не о том, какие препараты надо применять, а какие нежелательны, особенно с точки зрения вреда для когнитивных процессов, или описаны средства, никогда не применявшиеся в России либо применявшиеся весьма скромно (метилфенидат, декстроамфетамин, донепезил и др.).

Четкие рекомендации нужны еще и потому, что в отечественных нейротравматологических клиниках все психофармакологические препараты используются зачастую 
шаблонно, без учета индивидуальных показаний и противопоказаний. До недавнего времени не был исключением и наш институт - лекарства с психотропным действием здесь назначали не только психиатры, но и реаниматологи, нейрохирурги, неврологи.

Сплошной анализ назначений психотропных препаратов пострадавшим с тяжелой ЧМТ показал, что традиционные психотропные средства (нейролептики, антидепрессанты, транквилизаторы) были эффективны лишь у 41-44\% больных, нежелательные явления отмечены у 35-54\%. Положительное действие антиконвульсантов и нейрометаболических средств оказалось выше (66-70\%), но побочное все же наблюдалось достаточно часто (26-32\%).

Не один год ушел на то, чтобы исправить ситуацию, поднять эффективность фармакотерапии до 60-70\% и сократить долю наблюдений с негативным ее влиянием до 10$25 \%$. Этому способствовало внедрение следующих принципов использования: 1) атипичных нейролептиков вместо типичных; 2) четырехциклических или серотонинергических антидепрессантов вместо трициклических; 3) карбамазепинов и ламотриджина вместо барбитуратов; 4) индивидуально (с учетом ведущей симптоматики, преимущественной локализации поражения мозга и профиля индивидуальной асимметрии) подобранных нейрометаболических средств.

Индивидуализация нейрометаболической терапии стала возможной, в частности, в результате обнаружения неравномерного влияния препаратов на разные структуры мозга - стволовые, подкорковые, корковые, а также на функции и, соответственно, синдромы, зависящие преимущественно от левого и правого полушарий. При таком подходе нейромедиаторные препараты оказываются преимущественно воздействующими на левополушарную дисфункцию, а полипептидные и ГАМК-содержащие средства - на правополушарную, что может служить одним из важных критериев их выбора.

Особого внимания при проведении психофармакотерапии заслуживают пациенты-левши. Именно у них по сравнению с правшами гораздо более вероятны психопатологические побочные эффекты и менее эффективно традиционное лечение: например, антиконвульсанты (особенно при монотерапии) существенно реже обеспечивают полный контроль приступов.

Еще один разработанный психиатрической группой НИИ нейрохирургии им. Н.Н. Бурденко метод реабилитации - психостимулотерапия [23]. Это комплекс воздействий на больных, выходящих из комы и имеющих грубые дефекты психических процессов. Метод позволяет почти в 3 раза чаще достигать преморбидного уровня при полушарных поражениях и более быстрого возобновления отдельных психических процессов при срединностволовых нарушениях.

Таким образом, очевидна необходимость сосредоточения усилий психиатров, неврологов и представителей других медицинских дисциплин на: 1) ознакомлении широкого круга специалистов с последними достижениями нейропсихиатрии; 2) дальнейшем изучении патогенеза психических расстройств, улучшении диагностики и реабилитации пострадавших с тяжелым повреждением мозга.

\section{Л И Т Е P A Т У P A}

\section{1. Доброхотова Т.А. Нейропсихиатрия. М.:} Бином, 2006;304 с.

2. Очерки клинической нейропсихиатрии. Под ред. В.Н. Краснова, В.В. Калинина, И.В. Доровских. М.: Граница, 2010;216 с. 3. Arciniegas D.B., Beresford T.P.

Neuropsychiatry: an introductory approach. Cambridge - New York: Cambridge University Press, 2001;438 p.

4. Cummings J.L., Trimble M.R. Concise guide to neuropsychiatry and behavioral neurology. 2nd ed. Washington, DC: American Psychiatric Pub, 2002;275 p.

5. Cummings J.L., Mega M.S. Neuropsychiatry and behavioral neuroscience. Oxford - New York: Oxford University Press, 2003;414 p. 6. David A., Fleminger S., Kopelman M.D. et al. Lishman's organic psychiatry. A textbook of neuropsychiatry. 4th ed. Oxford - Hoboken, NJ: Wiley-Blackwell, 2009;933 p.

7. Gualtieri C.T. Brain injury and mental retardation: psychopharmacology and neuropsychiatry. Philadelphia: Lippincott Williams \& Wilkins, 2002;509 p.

8. Guide to neuropsychiatric therapeutics. Ed. by Coffey C.E., McAllister T.W., Silver J. Philadelphia: Lippincott Williams \& Wilkins, 2007;449 p.

9. Handbook of neuropsychiatry research. Ed. by Davies R.S. New York: Nova Science Publishers, 2010;203 p.
10. Mitchell A.J. Neuropsychiatry and behavioural neurology explained. Edinburgh - New York: W.B. Saunders, 2004;525 p.

11. Monaco F., Cavanna A.E. The neuropsychiatry of consciousness. New York: Nova Biomedical Books, 2007;162 p.

12. Moore D.P. Textbook of clinical neuropsychiatry. 2nd ed. London: Hodder Arnold, 2008;731 p.

13. Neuropsychiatry. 2nd ed. Ed. by Schiffer R.B., Rao S.M., Fogel B.S. Philadelphia: Lippincott Williams \& Wilkins, 2003;1252 p.

14. The American Psychiatric Publishing textbook of neuropsychiatry and behavioral neurosciences. Ed. by Yudofsky S.C., Hales R.E. Washington, DC: American Psychiatric Pub, 2008; 1332 p.

15. Брагина Н.Н., Доброхотова Т.А. Функциональные асимметрии человека. 2-е изд., доп. и перераб. М.: Медицина, 1988;237с.

16. Доброхотова Т.А., Брагина Н.Н. Функциональная асимметрия и психопатология очаговых поражений мозга. М.: Медицина, $1977 ; 358 \mathrm{c}$.

17. Потапов А.А., Коновалов А.Н., Корниенко В.Н. и др. Целевая научно-техническая программа - стратегический путь решения социальных и медицинских проблем черепно-мозговой травмы. URL:

http://www.internist.ru/articles/ochrana/ochra na_222.html

18. Owen A.M., Coleman M.R., Boly M. et al. Using functional magnetic resonance imaging to detect covert awareness in the vegetative state. Arch Neurol 2007;64(8):1098-102. 19. Гриндель О.М., Романова Н.В., Зайцев О.С. и др. Математический анализ электроэнцефалограмм в процессе восстановления сознания после тяжелой черепномозговой травмы. Журн неврол и психиатр 2006;12:47-51.

20. Захарова Н.Е., Потапов А.А., Корниенко В.Н. и др. Динамическое исследование структуры мозолистого тела и кортикоспинальных трактов с помощью диффузионнотензорной магнитно-резонансной томографии при диффузном аксональном повреждении. Вопр нейрохир 2010;3:3-10.

21. Зайцев О.С. Психопатология тяжелой черепно-мозговой травмы. М.: Медпрессинформ, 2011;336 с.

22. Warden D.L., Gordon B., McAllister T.W. et al. Guidelines for the pharmacologic treatment of neurobehavioral sequelae of traumatic brain injury. J Neurotrauma 2006;23(10):1468-601. 23. Зайцев О.С., Доброхотова Т.А., Гогитидзе Н.В. и др. Способ психофизиологической реабилитации больных с ЧМТ в посткоматозном периоде. Патент на изобретение №2073532, 1997. 